\title{
Customer Loyalty: An Empirical Study on Italian E-commerce Websites
}

\author{
Adinolfi Raffaele, Troisi Orlando \\ University of Salerno, Fisciano (SA), Italy
}

\begin{abstract}
In contemporary entrepreneurial environment based on customer retention, the growth of the internet has pushed the most dynamic businesses to compete in the electronic market. In literature, there are many studies showing how a company's brand affects customer loyalty. Less attention has been paid to the relationship between e-commerce website loyalty and e-customer loyalty. This paper can be included in a stream of research that applies the construct of loyalty to e-commerce. Thus, this study aims to analyze, within the electronic market, the elements influencing and determining the trust and loyalty of the e-customers. This research consists of a descriptive study carried out utilizing the survey method. The population in this study includes 421 e-customers of Italian online multi-brand portals. The instrument of data gathering was a web-questionnaire and the data analysis was based on regression. Findings show a positive relationship between three factors (website technological level, e-service quality, and brand) and e-customer trust. Furthermore, the correlation, among the three variables, trust as mediating variable, and e-customer's loyalty, has been revealed. Therefore, it can be basically assumed that trust builds e-customer loyalty.
\end{abstract}

Keywords: customer loyalty, e-commerce, brand, trust

\section{Introduction}

The extraordinary growth and development of the web that has been noticed in the past decades has dictated an important revolution in the trade market and has determined the development of a real "electronic market". Information technology and web communication are key aspects to the development of electronic commerce, that is why businesses hold internet and electronic commerce in high esteem, as the ideal place for their communicational and promotional activities in relation with their offers and services (Kotler \& Keller, 2006). Companies sell products through their website, through retailer website, or through e-commerce specialized websites. In literature, there are many studies showing how a company's brand affects customer loyalty. Less attention has been paid to relationship between e-commerce website loyalty and e-customer loyalty. This study seeks to explore the importance of e-commerce website. Internet is usually not considered as a safe place by its users, thus determining different grades of hesitancy that are the main obstacle to the development and increase of e-commerce. The development of secure and easy-to-use web servers and the diffusion of secure electronic payments systems have partly contributed to a progressive cultural mutation that

Adinolfi Raffaele, Ph.D., University of Salerno, Department of Management and Information Technology, Fisciano (SA), Italy. Troisi Orlando, Ph.D., University of Salerno, Department of Management and Information Technology, Fisciano (SA), Italy.

Correspondence concerning this article should be addressed to Orlando Troisi, Department of Management and Information Technology, University of Salerno,Via Giovanni Paolo II, 132, Fisciano (SA), 84084, Italy. E-mail: otroisi@unisa.it. 
has lessened the negative perception towards online transactions, easing the development of e-commerce. The two factors that contributed to the increase of online shopping are security and convenience as perceived by customers. A diffused mistrust does still exist, nevertheless holding back the development of the web for one's purchases. Internet users usually do not trust the quality of the items and of the services offered on the internet.

Some researches show how, by trust and word of mouth, an increase in satisfaction rates can be obtained, as well as an increase in the frequency of purchase and customer loyalty (Martin \& Camarero, 2009). According to Lin and Sun (2009), new web technologies give a better quality service and maximize web security, and these two factors would foster satisfaction and customer loyalty towards e-commerce (Parasuraman \& Grewal, 2000). Other authors (Gommans, Krishnan, \& Scheffold, 2001) have underlined how online purchase experiences are a further factor influencing inclination to online purchase for customers. Of course, the psychological perception of an online purchase is vastly different from that of a traditional purchase. Customer uncertainty is caused by the absence of a real interaction with the seller. Some studies showed that besides customer uncertainty on the quality of the services or of the products, the costs of the internet, the learning process, the security and the matter of privacy are additional factors having an impact on the customer decisional process. Nevertheless, the perceived risk of online shopping isn't the same among the different customers (Luarn \& Lin, 2003).

A research conducted on the perceptions of internet users highlights how the risk perceived by customers is inversely proportional to the level of trust towards a particular business (Johnson, Sivadas, \& Garbarino, 2008). Some internet users believe online purchases not to be advisable because of their uncertainty, some other web users underline, instead, the advantages of online purchases such as easily gathered information and the possibility of comparing prices (Waite \& Harrison, 2002).

For any e-commerce business, providing essential tools for customers, such as individual features, security norms, respect of privacy and different forms of payment, is fundamental.

A communicative ability is also highly important for a web site. The research by Chang and Wang (2008) shows the various effects that each element of the web site has, such as the project of the background color, icon model, dynamic scheme, and web border.

According to Aladwani (2006) customers are encouraged to purchase both by tangible and intangible elements. Tangible elements are technical adequacy of the web site, management of the contents, and the communicative ability of the web site related to its look and layout. Intangible elements are diffusion of the brand and previous purchase experiences.

Commercial web sites have to develop forms of communication with the aim to build trust underlining the positive features such as good reputation, security of transactions, tracking of operations (Martin \& Camarero, 2009).

The main focus in building and keeping a relationship between seller and customer is trust that is the essential principle to obtain customer long term attention (Chiu, Chang, Cheng, \& Fang, 2009).

In the electronic market, even more than in the traditional market, success in keeping good customers is the key to a successful business (M. L. Roehm, Pullins, \& H. A. Roehm, 2002). That is why online businesses should develop adequate strategies to persuade customers to re-purchase.

The research (Roehm et al., 2002) shows how the business income grows stunningly in relation with 
customer trust. Consequently, a minor change in the number of faithful customers modifies significantly the value of the business. An interesting research classifies internal and external discussion factors and has tried to explore the role of external factors such as, the functionality of the web site (technological factors), quality of the service, and influence of the brand in creating and establishing customer trust with the aim of making them faithful (Dick \& Basu, 1994).

\section{Literature Review}

\section{Communication, Perceived Risk, Trust, and Loyalty}

Traditional market forms of communication which have a bigger influence on purchase behaviors are direct communication between the seller and the purchaser and indirect communication on the retail site. The main focus of the seller communication is just on making the purchaser serene about the immediate features of the transaction (quality of the product/service, methods of payment, etc.) and on the future characteristics of the relation (guarantee, services of technical assistance, etc.). In the electronic market, direct communication between purchaser and seller is missing; that is why the feeling of insecurity from the purchaser is heightened and influences the purchasing behavior of the customer (Laroche, Yang, McDougall, \& Bergeron, 2005). Perceived risk has got a primary role in customer behavior in the electronic market (Corbitt, Thanasankit, \& Yi, 2003). Risk can be defined as a psychological condition marked by a previous negative purchase experience, making it harder to evaluate the effects on customer behavior (Chiu et al., 2009).

Online communication must be mainly aimed to reduce the perceived risk and to increase customer trust. Trust is important in every aspect of social life. It facilitates bargaining and negotiations reducing transaction costs. Trust definition refers to consumer's psychological state and to multi-dimensional notion that confederates cognitive or affective trust (Johnson \& Grayson, 2005). Someone's cognitive trust derives from logic and rational motives, while internal feelings and sensations influence the establishment of an emotional loyalty (Cigliano, Georgiadis, Pleasance, \& Whalley, 2000).

There are many definations of trust, many of whom consider trust as a state, a belief, or a positive expectation. Sztompka (1999) has defined trust as the expectation that other people, groups or institutions with whom one gets in contact - interact and cooperate-will act in ways leading to our well-being. Because in most cases one cannot be sure of that, as others are free agents, trust is a sort of gamble involving some risk (Dainesi, 1999).

Trust is considered among the most important factors for the promotion of business relations, particularly regarding the online world. Many researches have acknowledged the importance of trust in relation with online shopping and transactions. Trust builds a positive perception of the behavioral perspective of the online purchaser and influences purchase intentions of the customer, his satisfaction and loyalty (Ganesan, 1994).

Risk and trust represent two psychological states highly influencing the behavior of the customer, during the online shopping process (Chang \& Chen, 2008).

Brand loyalty in the online market is very important. Nowadays companies are moving forward to maintain and keep customers loyal. Brand loyalty is defined as the extent of the faithfulness of consumers to a particular brand, expressed through their repeating purchases, untouched by marketing pressure generated by the competing brands (Duffy, 1998). The first signal of brand loyalty is shopping iteration based on cognitive and emotional evaluation factors determining the customer's approach (Johnson et al., 2008). In comparison 
with traditional market, making the customers loyal is even more important because it plays a positive role in the perception of security and influences the perceived risk level.

There are different studies on concepts of trust and fidelity with different models of interpretation. These studies refer to specific items or services: cars, beauty products, insurance policies, bank services, commercial services, and so on. In this research, a conceptual model is applied to the electronic market, already adopted referring to particular segments of business, to evaluate the elements determining customer trust and loyalty in the field of electronic commerce.

\section{Website Technological Level and E-service Quality}

Online shopping portals allow customers to choose different items and services according to their own needs and to ask for any eventual personalization. The price of the service or the item is paid online (in Italy the option of paying the carrier is still popular when the product is received, lessening the risk linked with electronic methods of payment). The purchaser's first concern is to find an online shopping portal that is safe and easy to use. In the electronic market, according to Harris and Goode (2004), consumers' choices depend on four factors: the convenience of the website, the customer's autonomy, a feeling of customer relation, and trust to the online shopping portal. The first two elements are linked with rational motivations while the remaining two are linked with emotional aspects and connected to the customer's long term loyalty.

In literature, different models have been developed to measure the relation between the website's technical features and the inclination of the customer. The referral theory, proposed by Davis (1989) and vastly developed in the following years (Venkatesh \& Davis, 2000; Venkatesh, Morris, F. D. Davis \& G. B. Davis, 2003), is known as Technology Acceptance Model (TAM). This theory aims to evaluate how the acceptance of technology influences its own use. TAM theory is based on this idea: Perceived Usefulness (PU) and Perceived Easiness of Use (PEOU) determine how users act towards technology and the extent of its use. The online purchaser's decisions are directly linked with his degree of acceptance of technology (Shih, 2004), making online shopping easier to increase customer's satisfaction and, consequently, his long term loyalty (Lin \& Sun, 2009).

The quality of the website can influence the purchaser's attitude related to both the perceived security and the possibilities of choice. The quality of the website can be evaluated by analyzing four aspects: technical adequacy, quality of contents, specific contents, and graphic features. This evaluation must be put together by the consumer's point of view. Among all the elements, technical adequacy can be considered as the most critical item with the aim of evaluating the quality of the website. Quality of contents represents, on a scale of importance, the second evaluating criterion for a website. With regard to e-commerce websites, quality of contents can be referred to the following elements: customer service, security payment privacy, and internal search engine (Akbar \& Parvez, 2009).

The result of a research has showed how satisfaction among online purchasers is influenced by three factors: TAM, transaction costs analysis (TCA), and service quality. The research (Lin \& Sun, 2009) shows how TAM is useful and underlines that it influences, in a determining way, customer attitude and the inclination to re-purchase.

\section{Brand}

The brand of the website, that is the name or the symbol illustrating an item or an exclusive service thus setting it apart from other competitors, is considered intellectual property. Two features determine the value of the brand: The first is known as "consciousness of brand", while the second is represented by the image of the 
brand. The consciousness is given by the memory and the acknowledgement of the brand, while the image is composed by various mental connections to the brand the consumer does.

Pre-existing purchase experiences make it easier to recognize a website and its name. The image of the brand takes its shape accounting the customer's satisfaction levels, the previous purchase experiences and word of mouth. Creating and using a brand are fundamental to online transactions. The notoriety and fame of the brand build trust and reduce risks perceived by users who can use the web in an easier way (Zeheir, Sahin, Kitapci, \& Ozsahin, 2011).

Brand credibility allows us to face the main obstacle to the diffusion of online purchases: absence of trust. The brand is a critical element in the relation between business and consumer. The brand can be used to loyalize customers, its persuasive role giving the opportunity to get new clients. Trust in the brand is the base of long lasting relations between business and consumers. A famous brand makes customers secure about the quality of the products, thus determining trust and loyalization. When well-known products are purchased, the only risk perceived by the consumer is related to the site manager. The perceived risk is almost close to none if the product/service is purchased directly on the manufacturer website (Salo \& Karjaluoto, 2007).

Previous experiences in using a website have a positive influence on consumer trust and the notoriety of the website's brand. Gefen's research (2000) has underlined that e-customer satisfaction is influenced by an easy use of the website and its security levels as perceived during the phase of the online purchase.

Some authors have underlined how the businessman must be able to activate the virtuous spiral, satisfaction, loyalty, repurchase. This spiral favors the notoriety of the business brand so making the efforts by other businesses to get clients by inducing them to modify their own choices in vain (Tsai \& Huang, 2007).

\section{Research Methodology}

This research includes four personal questions and 25 attitude questions in order to study the relationships among website technological level, e-service quality, brand, e-customer trust, and e-customer loyalty. The questionnaire has been administered to 500 customers randomly selected among customers of five Italian online portals. The analysis was not referred to those consumers who make their purchases on the manufacturer websites but to those who use multi-brand portals specialized in e-commerce. There are 421 people who have answered the questions thoroughly. Since the population of the research is very broad, an earlier study had been done before the main research was completed. The primary research included 20 questionnaires in each of online shopping portal. The questionnaire was a researcher-made one and it included seven questions about technical features, five questions about website service quality, four questions about brand, five questions about trust, four questions about customer loyalty, and finally four personal questions had been asked by customers. The measuring scale of items was Likert Scale analyses in which number 1 stands for strongly disagree, number 7 stands for strongly agree, and number 4 stands for no opinion.

\section{Research Construct}

This model is elaborated combining Shih (2004) and Aladwani's models (2006) with researchers' evaluation. The model is presented in the figure 1. This model includes three independent variables including website technological level, e-service quality, and brand; and the dependent variable is trust. Furthermore, the research study examines the association among the three mentioned independent variables, trust (as mediate variable), and e-customer's loyalty. 


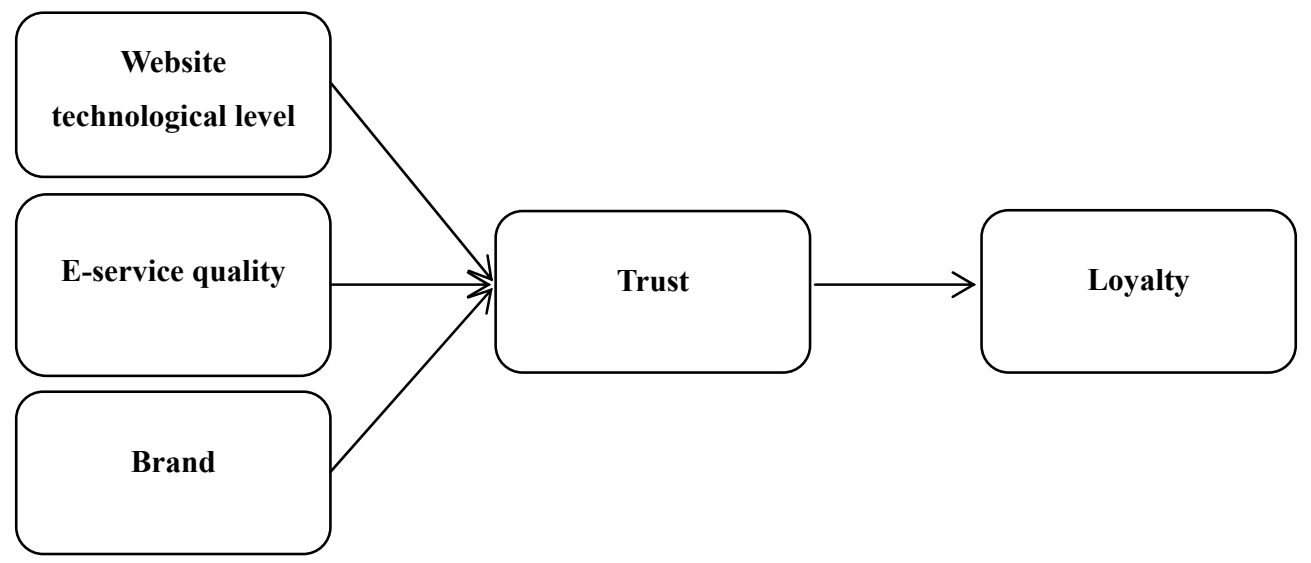

Figure 1. Research framework.

\section{Hypotheses Development}

The current research is a descriptive research which is done in a survey method and tries to study the effects of three independent variables on e-customer loyalty in Italian online marketplace by means of regression method. Pearson correlation gained by statistical analyzing of acquired data shows the existence or lack of existence of relationship between independent variables and dependent variables. The research hypotheses have been arranged as follows:

(1) Website technological level is related to customer trust;

(2) Website service quality is related to customer trust;

(3) Brand is related to customer trust;

(4) Trust, as mediating variable, is related to e-customer loyalty;

\section{Data Analysis}

The data were collected and coded, and then the raw data were categorized and checked for error elimination. Since there are multiples variables, the study needs to use multivariate analysis and also descriptive approach. The data was populated in SPSS to test the correlation between variables and moderating effects. Capability of data will also be accomplished through the reliability test using Cronbach's alpha that is a measure of internal consistency and of connection among the items as a group. In Table 1, the results of Cronbach's alpha reliability test are presented.

Table 1

Results of Cronbach's Alpha Reliability Test

\begin{tabular}{ll}
\hline Variables & Cronbach's alpha \\
\hline Website technical features & 0.741 \\
Website service level & 0.711 \\
Brand & 0.804 \\
Trust & 0.786 \\
E-Customer loyalty & 0.726 \\
\hline
\end{tabular}

From Table 1, it can be inferred that the results of Cronbach's Alpha reliability coefficient for all variables are above 0.07 , which are perceived to be acceptable and reliable. As such measurement tools for this study are reliable, researcher can proceed for further analysis (Nunnally, 1978). 


\section{Respondent Profile}

In this section, participants' socio-economic data were studied and interpreted in accordance with the research goals. Table 2 shows the descriptive analysis such as frequency and percentage of respondents for each category.

Table 2

Respondent Profile

\begin{tabular}{llcc}
\hline & & Frequency & Percentage \\
\hline \multirow{2}{*}{ Gender } & Male & 227 & $53.92 \%$ \\
& Female & 194 & $46.08 \%$ \\
\hline & Total & 421 & $100.00 \%$ \\
\hline \multirow{3}{*}{ Age } & $<25$ & 63 & $14.96 \%$ \\
& $26-35$ & 107 & $25.42 \%$ \\
& $36-45$ & 141 & $33.50 \%$ \\
\hline \multirow{4}{*}{ Net income } & $46-55$ & 71 & $16.86 \%$ \\
$(€$ per year) & $>55$ & 39 & $9.26 \%$ \\
\hline & Total & 421 & $100.00 \%$ \\
\hline & $<15,000$ & 98 & $23.28 \%$ \\
& $15,001-50,000$ & 176 & $41.80 \%$ \\
& $50,001-150,000$ & 103 & $24.47 \%$ \\
& $>150,000$ & 44 & $10.45 \%$ \\
\hline \multirow{3}{*}{ Education level } & Total & 421 & $100.00 \%$ \\
& Less than high school diploma & 46 & $10.93 \%$ \\
& High school diploma & 197 & $46.79 \%$ \\
& Degree & 139 & $33.02 \%$ \\
\hline
\end{tabular}

From Table 2, 227 (53.92\%) of participants were male and 194 (46.08\%) of participants were female in this study. This shows that male participation in this study was greater than female. However, the result of $t$-test shows no significant differences between two categories.

In terms of the age of participants, total of $75.78 \%$ of participants were between 25 to 55 years of age and other $24.22 \%$ were less than 25 or above 55 years of age. The first category with 141 (33.50\%) participants was between 36 to 45 years of age. The second largest group of respondents belonged to the category between 26 to 35 years of age. The ANOVA test indicates no significant difference among age groups.

There are four groups determined for education level of the participant in this study. There are $10.93 \%$ of respondents who had no high school diploma, the second category with 197 (46.79\%) participants had high school diploma, and the second largest group of respondents had graduated degree. The ANOVA test again indicates no significant difference between groups.

In terms of the income level of the respondents, $176(41.80 \%)$ of participants had income of $15000 €$ to $40000 €$. This shows that majority of the study's respondents were from medium and low incomes. The next largest category belonged to respondents who had income between $40001 €$ to $100.000 €$ by $24.47 \%$ of participation. The ANOVA test shows no significant differences between the means of different categories of respondents by their income levels. The correlations between variables of this study are presented in next section. 


\section{Correlation Analysis}

To statistically demonstrate the effect of trust determinants on e-customer loyalty, the study explores the three dimensions namely: website technical features, e-service quality, and brand. Thus, Pearson's correlation analyses were carried out for each relationship to estimate the correlation of variables for the interval or ratio scales measurement. The result of Pearson's test suggests linear correlation among all variables and the regression results based on the factors affecting trust are reported in Table 3.

Table 3

Pearson Correlation Test

\begin{tabular}{lllll}
\hline Variable & Pearson correlation & Sig (1-tailed) & $R$-square & Result \\
\hline Website technical features & 0.863 & 0.000 & 0.692 & Positive association between \\
E-service quality & 0.711 & 0.000 & & independent variables and trust \\
Brand & 0.767 & 0.000 & & \\
\hline
\end{tabular}

From Table 3, the study conducted the regression analyses and tested hypotheses. According to findings, the model is significant at $p<0.05$ level regard to each variables. Website technical features with $p$-value of $0.000<0.05$, e-service quality with $p$-value of $0.000<0.05$, and brand with $p$-value of $0.000<0.05$ indicate the strong relationship between the independent variables and trust. The $R$-square value of 0.692 indicates that independent variables can almost $70 \%$ explain trust, although the significant correlation between independent variables and trust, the model summary and stepwise test show only website technical features as main predictor of trust in the model. The result of stepwise test is shown in Table 4.

Table 4

The Stepwise Analysis

\begin{tabular}{|c|c|c|c|c|c|}
\hline \multirow[b]{2}{*}{ Model } & \multicolumn{2}{|c|}{ Unstandardized coefficients } & \multicolumn{3}{|c|}{ Standardized coefficients } \\
\hline & Beta & Std. Error & Beta & $t$ & Sig. \\
\hline Constant & 0.614 & 0.161 & & 4.412 & 0.000 \\
\hline Technology & 0.821 & 0.039 & 0.837 & 22.912 & 0.000 \\
\hline
\end{tabular}

The result of Pearson correlation on e-customer trust as mediating variable and e-loyalty declares the value of $0.837>0.05$, which indicates the positive relationship among the variables. Finally, the research shows that three independent variables namely and respectively: website technical features, e-service quality, and brand on e-customer trust and e-customer trust lead to e-loyalty. The study confirms the researcher assumption and the arranged hypothesis.

\section{Discussion on Findings}

Based on findings which were acquired by analyzing the results of the first question of the hypothesis, one can come to the conclusion that there is a meaningful relationship between website technical features and creating e-customer trust. In other words, in any level the technology quality is growing and the e-customer trust is increasing in the same level. It has been also verified that there is a positive relationship between these factors to achieve e-customer loyalty for an internet portal as well. In order to meet the positive e-customer behavior, websites should have technical features aiming at allowing the e-customer to save time and money while they have online shopping efficiency. Also, by studying the results of the second hypothesis, it can be assumed that there is a meaningful relation between the qualitative and quantitative e-services level. It means 
that it is very important to implement technology capable of providing new personalized services such as on-call customer support system, tracking system, easy and convenient web-area, e-loyalty programs. Furthermore, this paper strives to prove the importance of a well-known website brand. By considering the results of the third hypothesis, it can be concluded that there is a meaningful relation between website brand and trust. In fact, the website brand recognition in many cases placed over e-service quality and technology to attract e-customers. The study shows that e-customer trust strongly relies on website brand. Moreover, study shows that providing a convenient and trusted online environment leads to more satisfaction and strongly increases loyalty and inclination to repurchase on the same website. Trust is a primary step to create a loyal e-customer and there is a direct effect between the three factors considered and trust, whereas indirect effect with e-loyalty. In this research, it has been only studied how customers specialized in e-commerce websites deal with various brands. Future research could incorporate data from e-customer groups' purchases directly on websites of manufacturers of goods and services. It would be very interesting to study the different impact of manufacturer brand reputation and of e-commerce website recognition on e-loyalty. This information could be useful to define or improve business strategy.

\section{Conclusions}

In a hypercompetitive market, customer retention is more profitable than customer acquisition. For this reason, particularly businesses who decide to join the electronic market have to establish long term relationships with consumers. Indeed, online purchases are frequently perceived by e-shoppers as more complicated and safer than traditional.

Starting from the theoretical construct of loyalty, this paper aims to bridge the gap regarding the unexplored relationship between e-commerce website loyalty and e-customer loyalty.

The recent interest in e-business has not always created an impact on business strategies involved in e-commerce websites building.

However, the significance of trust and its effects on loyalty must be taken into account in developing e-commerce websites, especially referring to the dimensions which can influence trust, such as website's technological level, e-service quality, and brand awareness. Besides, an overview of trust and loyalty definitions and features has confirmed their close connection.

From this perspective, technical adequacy, service quality, and brand building strategies contribute to increasing e-customer's satisfaction and decreasing the perceived risk level.

So, this study has attempted to investigate and statistically demonstrate the connection among website technical features, trust, and loyalty.

First of all, the current research has shown the correlation between the three independent variables selected (website technical features, e-service quality, and brand) and trust. Furthermore, Pearson's correlation on e-customer trust as mediating variable and e-loyalty has revealed the positive relationship among the variables.

Finally, it can be supposed that there is a direct effect between the three factors considered and trust, whereas indirect effect with e-loyalty. The analysis confirms the early assumption.

These results could have practical implication in terms of benefits for researchers and businesses. Moreover, this work could represent a preliminary study of the suitable online business strategies to enhance loyalty. 


\section{References}

Akbar, M. M., \& Parvez, N. (2009). Impact of service quality, trust and customer satisfaction on customer loyalty. ABAC Journal, 29, 24-38.

Aladwani, A. (2006). An empirical test of the link between website quality and forward enterprise integration with web consumers. Business Process Management Journal, 12, 178-190.

Chang, H. H., \& Chen, S. W. (2008). The impact of online store environment cues on purchase intention: Trust and perceived risk as a mediator. Online Information Review, 32, 818-841.

Chang, H. H., \& Wang, I. C. (2008). An investigation of user communication behavior in computer mediated environments. Computers in Human Behavior, 24, 2336-2356.

Chiu, C. M., Chang, C. C., Cheng, H. L., \& Fang, Y. H. (2009). Determinants of customer repurchase intention in online shopping. Online Information Review, 33, 761-784.

Cigliano, J., Georgiadis, M., Pleasance, D., \& Whalley, S. (2000). The price of loyalty. Mckinsey Quarterly, 4, 68-77.

Corbitt, B., Thanasankit, T., \& Yi, H. (2003). Trust and e-commerce: A study of consumer perceptions. Electronic Commerce Research and Application, 2, 203-215.

Dainesi, E. (1999). Trust in electronic markets. Ovvero l'importanza dei pagamenti sicuri online. Web Marketing Tools, 23, 1-15.

Davis, F. D. (1989). Perceived usefulness, perceived ease of use and user acceptance of information technology. MIS Quarterly, 13, 319-340.

Dick, A. S., \& Basu, K. (1994). Customer loyalty: Toward an integrated conceptual framework. Journal of the Academy and Science, 22, 99-133.

Duffy, D. L. (1998). Customer loyalty strategies. Journal of Consumer Marketing, 15, 435-448.

Ganesan, S. (1994). Determinants of long-term orientation in buyer-seller relationship. Journal of Marketing, 58, 1-19.

Gefen, D. (2000). E-commerce: The role of familiarity and trust. Omega, 28, 725-737.

Gommans, M., Krishnan, K. S., \& Scheffold, K. B. (2001). From brand loyalty to e-loyalty: A conceptual framework. Journal of Economic and Social Research, 3(1), 43-58.

Harris, L. C., \& Goode, M. M. H. (2004). The four levels of loyalty and the pivotal role of trust: A study of online service dynamics. Journal of Retmailing, 80, 139-158.

Johnson, D., \& Grayson, K. (2005). Cognitive and affective trust in service relationships. Journal of Business Research, 58, 500-507.

Johnson, M. S., Sivadas, E., \& Garbarino, E. (2008). Customer satisfaction, perceived risk and affective commitment: An investigation of directions of influence. Journal of Services Marketing, 22, 353-362.

Kotler, P., \& Keller, K. L. (2006). Marketing management. New Jersey: Pearson Prentice Hall.

Laroche, M., Yang, Z., McDougall, G., \& Bergeron, J. (2005). Internet versus bricks-and-mortar retailers: An investigation into intangibility and its consequences. Journal of retailing, 81, 251-267.

Lin, G. T., \& Sun, C. C. (2009). Factors influencing satisfaction and loyalty in online shopping: An integrated model. Online Information Review, 33, 458-475.

Luarn, P., \& Lin, H. H. (2003). A customer loyalty model for e-service context. Journal of Electronic Commerce Research, 4(4), 156-167.

Martin, S. S., \& Camarero, C. (2009). How perceived risk affects online buying. Online Information Review, 33, 629-654.

Nunnally, J. C. (1978). Psychometric theory (2nd ed.). New York: McGraw-Hill.

Parasuraman, A., \& Grewal, D. (2000). The impact of technology on the quality-value-loyalty chain: A research agenda. Journal of the Academy of Marketing Science, 28(1), 68-174.

Roehm, M. L., Pullins, E. B, \& Roehm, H. A. (2002). Designing loyalty—Building programs for package goods brands. Journal of Marketing Research, 39(2), 202-213.

Salo, J., \& Karjaluoto, H. (2007). A conceptual model of trust in the online environment. Online Information Review, 31, 604-621.

Shih, H. P. (2004). An empirical study on predicting user acceptance of e-shopping on the web. Information and Management, 41, 351-368.

Sztompka, P. (1999). Trust: A sociological theory. Cambridge: Cambridge University Press.

Tsai, T. H., \& Huang, C. H. (2007). Determinants of e-repurchase intentions: An integrative model of quadruple retention drivers. Information \& Management, 44, 231-239. 
Venkatesh, V., \& Davis, F. D. (2000). A theoretical extension of the technology acceptance model: Four longitudinal field studies. Management Science, 46, 186-204.

Venkatesh, V., Morris, M. G., Davis, F. D., \& Davis, G. B. (2003). User acceptance of information technology: Toward a unified view. MIS Quarterly, 27, 425-478.

Waite, K., \& Harrison, T. (2002). Consumer expectations of online information provided by bank websites. Journal of Financial Services Marketing, 6(4), 309-322.

Zeheir, C., Sahin, A., Kitapci, H., \& Ozsahin, M. (2011). The effects of brand communication and service quality in building brand loyalty through brand trust: The empirical research on global brands. Social Behaviour Science, 24, 1218-1231. 